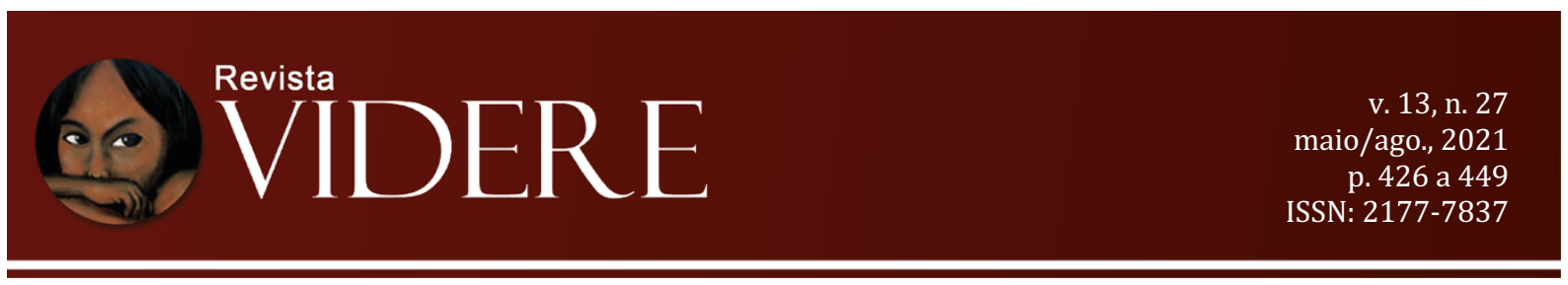

\title{
DITADURA MILITAR: ESTADO DE EXCEÇÃO PARA O PANTANAL
}

DIE MILITÄRDIKTATUR: DER AUSNAHMEZUSTAND ZUM PANTANAL

\author{
MILITARY DICTATORSHIP: THE STATE OF EXCEPTION FOR THE PANTANAL
}

\begin{abstract}
Carlos Augusto de Oliveira Diniz
Doutor em Direito pela Pontifícia Universidade Católica de São Paulo (PUC-SP)

Universidade Federal de Jataí-UFJ

carlosaugustodiniz@hotmail.com

OrcidID: https://orcid.org/0000-0001-6639-029X

Estefânia Naiara da Silva Lino Doutora em Direito pela Pontifícia Universidade Católica de São Paulo (PUC-SP) Universidade de Rio Verde - UNIRV estefanialino@msn.com OrcidID: https://orcid.org/0000-0002-8330-7694

Sirlene Moreira Fideles Mestre em Educação pela Universidade Católica Dom Bosco (UCDB)

Universidade Federal de Jataí-UFJ sirlenefideles@gmail.com

OrcidID: https://orcid.org/0000-0003-3719-5705
\end{abstract}

Resumo: O objeto deste artigo são os impactos do estado de exceção sobre o Pantanal. O objetivo geral é demonstrar que o estado de exceção não se restringe a ramo específico do direito, pois sua existência depende da suspensão de todo o ordenamento jurídico. O objetivo específico é a demonstração de que o estado de exceção também se nota no direito ambiental, sobretudo, quando promoveu a destruição da bacia do alto taquari e consequentemente do ciclo das águas do Pantanal por intermédio de políticas de incentivo a ocupação do Cerrado brasileiro onde estão as nascentes da bacia do alto taquari. Optamos pelo método dedutivo e como metodologia utilizou-se a pesquisa bibliográfica. Concluímos que o estado de exceção busca eliminar os indesejáveis ao sistema capitalista, sobretudo índios, ribeirinhos e camponeses, por intermédio da suspensão de todo o ordenamento jurídico e não somente dos direitos e garantias individuais.

Palavras-chave: Ditadura militar. capitalismo. estado de exceção. rio Taquari. Pantanal.

Zusammenfassung: Der objekt auf diese artikel ist die auswirkung der ausnahmezustand über den Pantanal. Das hauptziel ist als zeigen das der ausnahmezustand nicht begrenzt war zu einen 
spezifische rechts zweig, weil ihr bestand hängt an der total suspension auf der Rechtsordnung $a b$. Das spezifische ziel ist die demonstration als der ausnahmezustand kan auch bemerkt sein an dem Umweltrecht, vor allem, wen die zerstörung das Taquarí flussgebiet realisiert war und daher die zerstörung der Pantanal waser zyklus durch die förderung politiken, die besetzung die brasilianische savanne wo die quellen von das Taquari flusgebiet sind. Wir haben der deduktive methode gewählt und als methodologie haben wir die bibliografische untersuchung gebraucht. Wir haben als ergebnis erreicht das der ausnahmezustand hat als ziel die unerwünschte das kapitalistische system löschen, vor allem indianer, anrainer bewohner und bauern durch die total rechtsordnung suspension und nicht nur die individuelle rechte und garantien.

Schlüsselwörter: Militärdiktatur. kapitalismus. ausnahmezustad. Taquarí fluss. Pantanal.

Abstract: The goal of this article is about the impacts of the state of exception over the Pantanal. The general goal is to demonstrate that the state of exception is not restricted to a specific branch of the law, because its existence depends on the suppression of the whole legal order. The specific goal is the demonstration that the state of exception is also noticed on the environmental law, especially, when it promoted the destruction of the alto taquari basin and consequently the cycle of waters of the Pantanal through the supporting policies of the Brazilian cerrado occupation where the sources of the alto taquari basin are located. We opted by the deductive method and as the methodology we used the bibliographic research. We concluded that the state of exception intents to eliminate the undesirable to the capitalist system, especially Indians, riparian and rural people, through the suppression of the whole legal order and not only the individual rights and guarantees.

Keywords: Military dictatorship. capitalism. state of exception. Taquari river. Pantanal

\section{Introdução}

Este artigo é produção oriunda de projeto de pesquisa em andamento cujos dados já levantados permitiram a construção do pensamento delineado neste texto que é a abordagem sobre os impactos da ditadura civil-militar sobre o ecossistema do Pantanal do Brasil.

Importante ratificar que o presente trabalho tem como objetivo geral a demonstração de que no estado de exceção a suspensão da ordem jurídica possui um caráter genérico, ou seja, um sentido de gênero que abrange as mais variadas espécies como o direito constitucional, direito penal, processual penal, ambiental, etc. Como objetivo específico centrou-se a análise no campo do direito ambiental sobre os efeitos do estado de exceção, no ecossistema pantaneiro, como consequência direta do avanço do agronegócio sobre as nascentes de importantes bacias hidrográficas localizadas no Cerrado brasileiro.

Partindo com o método dedutivo o desenvolvimento do presente texto foi distribuído em três tópicos. A metodologia escolhida e aplicada foi a pesquisa bibliográfica. Primeiramente no tópico intitulado "Natureza e Trabalho no Capitalismo" se discute a relação do homem com a natureza por intermédio do trabalho, mas principalmente como essa relação homem com a 
natureza se alterou à medida que o capitalismo surgiu e se consolidou como o modo de produção dominante.

No tópico seguinte nominado de "Ditadura civil-militar: o Estado de Exceção Ambiental" nos debruçamos sobre o tema da ditadura civil-militar brasileira como exemplo de um estado de exceção. Especificamente demonstrou-se como opera a lógica do estado de exceção em torno de dois elementos fundantes que são a regra e a exceção, além da característica de situar-se num limbo entre o direito e a política o estado de exceção age sempre amparado pelo direito e voltado para seu espaço interno, no caso ambiental esse espaço interno que é dominado pelo estado de exceção foi o território do Cerrado.

O último tópico "O Pantanal na ditadura civil-militar" procurou-se demonstrar de modo direto e específico como o regime de exceção produziu impactos diretos no ecossistema do Pantanal impactos decorrentes da suspensão da ordem jurídica, natural no estado de exceção, no âmbito do direito ambiental. Após o desenvolvimento apresentamos a conclusão onde se condensou as informações presentes no desenvolvimento.

\section{Natureza e Trabalho no Capitalismo}

Ao longo da evolução humana o relacionamento do homem com a natureza é um processo decisivo de construção antropológica e histórica da humanidade, pois percebe-se perfeitamente a relação de temor inicial para a de dominação da natureza. A dominação da natureza se desenvolve paralelamente a medida que a percepção humana do tempo também se altera.

Neste sentido, essa nova percepção do homem sobre o tempo é pano de fundo de transformações econômicas e sociais de grande impacto na vida social, cite-se o movimento de superação da compreensão do tempo cíclico para o tempo linear como sendo crucial para a percepção dessa nova relação homem $\Leftrightarrow$ natureza, homem $\Leftrightarrow$ tempo.

[...] na Europa medieval, e também na Antiguidade, o tempo não era concebido como uma variável contínua, mas dividido em várias estações, divisões do Zodíaco e assim por diante, cada uma exercendo influência específica. Em outras palavras, o tempo mágico ainda não tinha sido sucedido pelo tempo científico. Ao longo do período medieval, os conceitos de tempo cíclico e linear existiram em conflito. Os cientistas e eruditos, influenciados pela astronomia e pela astrologia, tendiam a enfatizar o conceito cíclico. A concepção linear era promovida pela classe mercantil e pela ascensão de uma economia monetária. Pois enquanto o poder se concentrava na propriedade da terra, o tempo era considerado abundante e associado ao ciclo imutável do solo. Mas com a circulação da moeda deu-se ênfase à mobilidade. O ritmo de vida aumentou, e o tempo passou a ser considerado algo valioso que parecia escapar continuamente [...]. (WHITROW, 2005. p. 25). 
A alteração do tempo cíclico para o tempo linear ocorreu em paralelo com a própria superação do feudalismo pelo capitalismo. Neste sentido, o tempo linear, que assumiu formas subjetivas e filosóficas, é fundamental para outro conceito que é o conceito de trabalho, pois o trabalho no tempo cíclico era dominado pela natureza, já no tempo linear será a natureza subjugada pelo trabalho. Essa é a ruptura que se efetivou e se intensificou até o momento contemporâneo. Em O Capital Karl Marx pondera que:

[...] o trabalho é um processo de que participam o homem e a natureza, processo em que o ser humano, com sua própria ação, impulsiona, regula e controla seu intercâmbio material com a natureza. Defronta-se com a natureza como uma de suas forças. Põe em movimento as forças naturais de seu corpo - braços e pernas, cabeça e mãos -, a fim de apropriar-se dos recursos da natureza, imprimindo-lhes forma útil à vida humana. Atuando assim sobre a natureza externa e modificando-a, ao mesmo tempo modifica sua própria natureza. Desenvolve as potencialidades nela adormecidas e submete ao seu domínio o jogo das forças naturais. (MARX, 2011, p. 211).

Transformar a natureza mediante ação direta e intencional. Eis o ponto de onde erradia a compreensão básica do conceito de trabalho. Esse conceito acessado e processado permite que se tenha a dimensão do trabalho escondida no produto, mas além do processo o produto esconde algo que é o diferenciador entre trabalho e ação, se assim pudermos chamar, pois ação sem consciência não será trabalho, poderá ser qualquer outra coisa menos trabalho.

Uma aranha executa operações semelhantes às do tecelão, e a abelha supera mais de
um arquiteto ao construir sua colmeia. Mas o que distingue o pior arquiteto da melhor
abelha é que ele figura na mente sua construção antes de transformá-la em realidade.
No fim do processo aparece um resultado que já existia antes idealmente na
imaginação do trabalhador. Ele não transforma apenas o material sobre o qual opera;
ele imprime ao material o projeto que tinha conscientemente em mira, o qual constitui
a lei determinante do seu modo de operar e ao qual tem de subordinar sua vontade.
(MARX, 2011, p. 211).

De modo sucinto podemos dizer que a capacidade de idealização faz com que a ação humana se diferencie de qualquer outra ação, pois existem elementos básicos desta ação, ou deste processo, "Os elementos componentes do processo de trabalho são: 1) a atividade adequada a um fim, isto é o próprio trabalho; 2) a matéria a que se aplica o trabalho, o objeto de trabalho; 3) os meios de trabalho, o instrumental de trabalho". (MARX, 2011, p. 212). Neste ponto é importante estabelecer distinção entre os dois últimos elementos que compõem o processo de trabalho.

Todas as coisas que o trabalho apenas separa de sua conexão imediata com seu meio natural constituem objetos de trabalho, fornecidos pela natureza. Assim os peixes que se pescam, que são tirados do seu elemento, a água; a madeira derrubada na floresta virgem; o minério arrancado dos filões. Se o objeto de trabalho é, por assim dizer, filtrado através de trabalho anterior, chamamo-lo de matéria-prima. Por exemplo, o minério extraído depois de ser lavado. Toda matéria-prima é objeto de trabalho, mas nem todo objeto de trabalho é matéria-prima. O objeto de trabalho só é matéria-prima depois de ter experimentado modificação efetuada pelo trabalho. O meio de trabalho é uma coisa ou um complexo de coisas que o trabalhador insere entre si mesmo e o 
objeto de trabalho e lhe serve para dirigir sua atividade sobre esse objeto. Ele utiliza as propriedades mecânicas, físicas, químicas das coisas para fazê-las atuarem como forças sobre outras coisas, de acordo com o fim que tem em mira. (MARX, 2011, p. 212).

Ocorre que estes elementos apontados por Karl Marx reforçam a dimensão de que o conceito de trabalho está diretamente ligado à relação do homem com a natureza para a transformação da matéria. Porém, que não se tenha a compreensão apaixonada e excessivamente idealizada de que a transformação da natureza é algo ruim por essência, pois é justamente neste processo, em que o homem transforma a natureza pelo trabalho, que o homem também se transforma e se constrói.

Talvez o problema central do processo de transformação da natureza seja o fato de que no capitalismo tenha emergido uma concepção de que o homem não é parte de um conjunto biológico, ou seja, quando o homem se afasta da compreensão de impotência para uma ideia de dominação da natureza consequentemente ele não mais se enxerga como parte do ecossistema, mas como seu dono, seu proprietário, e, portanto distante do tempo cíclico.

Não é segredo que estamos enfrentando uma emergência ambiental planetária, que
coloca em perigo muitas espécies do planeta, incluindo nossa própria, e que a
catástrofe em curso tem suas raízes no sistema econômico capitalista. Ainda assim, os
perigos extremos que o capitalismo inerentemente causa ao meio-ambiente são
comumente mal-entendidos, dando margem à crença de que é possível a criação de
um novo "capitalismo natural" ou "capitalismo climático", em que o sistema muda de
inimigo do meio-ambiente, para seu salvador (Hawken e Lovins, 1999; Lovins e
Cohen, 2011). O maior problema de todas essas visões é que elas subestimam a
cumulativa ameaça à humanidade e à Terra nascente das existentes relações de
produção. De fato, a total enormidade da crise ecológica planetária, afirmo, só pode
ser entendida de um ponto de vista baseado na crítica marxista ao capitalismo.
(FOSTER, 2011, p. 87).

A ponderação acima ela é fundamental para que se possa compreender o contexto em que a relação homem $\Leftrightarrow$ natureza chegou, pois se o capitalismo é conduzido pela ideia de acúmulo de riquezas a todo custo, desconstruir essa lógica não é tarefa fácil se pensarmos que a mecânica da exploração tornou-se uma espécie de consenso involuntário na humanidade, ou seja, é como dizer que o capitalismo é incapaz de domar o mostro ideológico que ele mesmo criou.

A contribuição ecológica mais apontada de Marx, entretanto, encontra-se em sua teoria de fenda metabólica. Construindo a partir do trabalho do grande químico alemão Justus Von Liebig, Marx argumentou que ao transportar alimentos e fibras por centenas e milhares de quilômetros até os novos centros urbanos de produção industrial, onde as populações iam aumentando de maneira concentrada, o capital acabou por roubar do solo seus nutrientes, como nitrogênio, fósforo e potássio, que ao invés de serem retornados para a terra, criavam poluição nas cidades. Liebig chamava isso de "Raubbau" ou o sistema de roubo. Como Ernest Mandel disse em sua Teoria Econômica Marxista: Cientistas sérios, notadamente o alemão Liebig, chamaram a atenção para um fenômeno realmente perturbador, a crescente exaustão do solo, o Raubbau, resultante dos gananciosos métodos capitalistas de exploração que visam os maiores lucros no menor tempo. Enquanto sociedades agrícolas como 
China, Japão, o Egito antigo, etc, tinham o conhecimento de um modo racional de avançar com uma agricultura que conservou e aumentou a fertilidade do solo durante milhares de anos, o Raubbau capitalista foi capaz, em certas partes do mundo, de exaurir a camada fértil do solo...em meio século (Mandel, 1968: 295). Para Marx, esse Raubbau capitalista tomou a forma de "uma fenda irreparável" no interior da sociedade capitalista no metabolismo entre a humanidade e a terra - "um metabolismo prescrito pelas próprias leis naturais" - requerindo sua "restauração sistemática enquanto uma lei regulativa da produção social". Na industrialização da agricultura, ele sugeriu, a real natureza da "produção capitalista" foi revelada, em que "somente se desenvolve desabilitando simultaneamente as fontes originais de toda a riqueza o solo e o trabalhador". (FOSTER, 2011, p. 90/91).

Quando o homem não mais se enxerga como parte do ecossistema as alterações da natureza não mais serão instrumento de construção humana, mas sim instrumento de destruição da vida em seus mais diversos aspectos, mas para, além disso, a transformação da natureza passará a servia ao acúmulo capitalista.

A dominação do valor de troca sobre o valor de uso no desenvolvimento capitalista e
seus impactos ecológicos podem também ser vistos na fórmula geral do capital de
Marx, M-C-M'. O capitalismo é comumente descrito como um sistema conforme a
simples produção de mercadoria C-M-C, na qual o dinheiro é simplesmente um
intermediário no processo de produção e troca, começando e finalizando com valores
de uso particulares corporificados em mercadorias concretas. Em nítido contraste,
Marx explica que a produção e a troca capitalista tomam a forma de M-C-M', na qual
o capital-dinheiro é aplicado no trabalho e materiais para produzir uma mercadoria,
que pode ser vendida por mais dinheiro, ou seja, M', ou M + $\Delta$ m (mais-valia), ao final
do processo. A diferença crucial aqui é que o processo nunca termina, já que o
dinheiro ou um valor abstrato é o objeto. A M' é reinvestida no período seguinte,
resultando em M'-C-M', que leva a M'-C-M'"' no período após esse, e assim segue.
Para manter sua riqueza sob esse sistema, o capitalista deve continuar a busca para
estendê-la. A lei do valor, assim, constantemente sussurra para cada indivíduo
capitalista e para a classe capitalista como um todo: "Continue! Continue!”. Isso,
entretanto, requer a revolução incessante da produção para substituir a força de
trabalho e promover lucros a serviço de uma ainda maior acumulação. (FOSTER,
2011, p. 89/90).

O acúmulo, sempre o acúmulo, este é o objetivo do modo de produção capitalista, é pelo acúmulo que a burguesia arquiteta e aplica golpes de estado, promove guerras, destrói as subjetividades, suga a seiva da natureza como um parasita, para usarmos uma definição da biologia. Dito isso, vejamos a seguir a ditadura civil-militar e sua relação com o meio ambiente, sem perder de vista que ela está intimamente ligada ao modo de produção capitalista, ou melhor, é uma consequência natural do modo capitalista de produção.

\section{Ditadura civil-militar: o Estado de Exceção Ambiental}

No Brasil quando se dispõe a discutir o período de 1964 a 1985 é necessário que se faça uma abordagem mais rigorosa do ponto de vista histórico e sociológico, pois tal período é 
adequadamente conceituado quando nominado de ditadura civil-militar, ou ainda de ditadura empresarial-militar:

Nada é mais impactante na investigação sobre o papel dos civis ao longo do regime ditatorial do que a colaboração de grandes empresários no financiamento da estrutura da repressão. [...] O caso mais simbólico foi o da Operação Bandeirantes (Oban), criada em São Paulo após a decretação do Ato Institucional no 5 (AI-5). [...] Ficou conhecido o banquete organizado pelo ministro Delfim Netto no Clube São Paulo, antiga residência da senhora Viridiana Prado, durante o qual cada banqueiro, como Amador Aguiar (Bradesco) e Gastão Eduardo de Bueno Vidigal (Banco Mercantil de São Paulo), entre outros, doou o montante de 110 mil dólares para reforçar o caixa da Oban. Ao lado dos banqueiros, diversas multinacionais financiaram a formação da Oban, como os grupos Ultra, Ford, General Motors, Camargo Corrêa, Objetivo e Folha. Também colaboraram multinacionais como a Nestlé, General Eletric, Mercedes Benz, Siemens e Light. Um número incerto de empresários paulistas também contribuiu, já que a arrecadação de recursos contava com o apoio ativo da Federação das Indústrias do Estado de São Paulo (FIESP), por meio de seu presidente, Theobaldo De Nigris. Nos salões da FIESP, o ministro da Fazenda, Delfim Netto, era sempre visto fazendo palestras aos empresários, em reuniões onde se solicitavam recursos para financiar a Oban. (COMISSÃO NACIONAL DA VERDADE, 2014, $329 / 330)$.

Dessa forma, é necessário ressaltar a ligação entre os militares e fração da sociedade civil, especialmente do setor empresarial, visto que a atuação dos presidentes militares abriu caminho para que setores específicos tivessem caminho aberto para concretização da lógica capitalista de produção, portanto o que foi feito durante o período da ditadura civil-militar teve como objetivo proporcionar que determinados setores acumulassem riquezas em detrimento de quem não dominasse a terra, a indústria e o capital financeiro.

É importante difundir a compreensão de que o estado de exceção não se restringe ao campo do direito penal, mas a todo o ordenamento jurídico, portanto no direito ambiental o estado de exceção também se nota. E como todo estado de exceção seu objetivo busca realizar apenas um propósito que é a eliminação dos inimigos indesejados. No caso concreto do agronegócio o inimigo é tudo que impeça o acúmulo de riqueza por intermédio da destruição ambiental.

Neste sentido, a ditadura civil-militar não destruiu apenas a integridade física e psicológica das pessoas que torturou. A ditadura civil-militar não destruiu apenas a vida das pessoas que assassinou, pois destruiu também o meio ambiente, o Pantanal especificamente quando incentivou a lógica do agronegócio. Portanto, a ditadura civil-militar no Brasil como estado de exceção que foi, destruiu o Pantanal quando estimulou o que podemos definir como a marcha para o Oeste do Brasil estimulando o Raubbau capitalista (FOSTER, 2011).

Como demonstrado anteriormente a Bacia do Alto Taquari nasce no Cerrado brasileiro e então segue seu curso até o Pantanal. Neste sentido o processo de ocupação do cerrado é o 
pano de fundo de toda a destruição ambiental pela qual passou e ainda passa o Pantanal. Importante trazer uma definição do Cerrado:

O cerrado é vegetação típica do Brasil Central. O Brasil Central é constituído por Goiás, Tocantins, Mato Grosso, Mato Grosso do Sul, oeste da Bahia, oeste de Minas Gerais e o Distrito Federal. O cerrado também se estende para fora do Brasil Central em penínsulas: para o norte, no sul do Maranhão e Piauí, para o noroeste como uma língua através de Rondônia, e para o sul como uma série de áreas disjuntas em São Paulo. Também ocorre em áreas pequenas e disjuntas no Nordeste, encravadas na caatinga. Contudo, sua distribuição geográfica não é precisamente delimitada, em função de dificuldades de classificação dos espaços naturais e da falta de mapeamentos em escala adequada. Vale ressaltar ainda que parte considerável do espaço natural brasileiro, incluindo as áreas de cerrados, foi alterado pelo homem, o que dificulta ainda mais a delimitação precisa do domínio dos cerrados. Sua área nuclear ocupa uma extensão de, aproximadamente, $1.830 .000 \mathrm{Km}^{2}$, equivalendo a cerca de $21 \%$ do território brasileiro. Os estados de Mato Grosso, Mato Grosso do Sul, Goiás, Tocantins e Minas Gerais concentram $73 \%$ da área total de cerrados do país. (JESUS, 1988, p. 21).

Por sua localização centralizada no território brasileiro o Cerrado possui uma característica importante para o regime de águas do Brasil, pois é a fonte de importantes bacias hidrográficas nacionais.

A área nuclear do cerrado abrange os divisores de águas separadores dos grandes sistemas hidrográficos do território brasileiro. Ao sul, abrangendo parte da bacia do Paraná; a sudoeste, do Paraguai; ao norte, da Bacia Amazônica (Tapajós, Xingu, Araguaia e Tocantins); a nordeste, do Parnaíba e do Mearim; a leste, do São Francisco; além de cabeceiras das bacias do Madeira, ao norte, e do Jequitinhonha, a leste. O regime fluvial dos rios da região dos cerrados apresenta diferenças notáveis, não somente devido às características físicas de suas bacias de drenagem (relevo e tipo de terreno), mas, também, pelas diferenças climáticas a que estão submetidos. O relevo da região dos cerrados caracteriza-se, principalmente, pela predominância de superfícies tabulares e aplainadas, conhecidas como chapadas. Outras formas de relevo regional são as depressões, com destaque para a Planície do Araguaia e o Pantanal Mato-Grossense, e as colinas. (JESUS, 1988, p. 25).

A magnitude do ecossistema Cerrado é reforçada quando se destaca a sua influência direta na vida de rios como Paraná, Paraguai, Tapajós, Araguaia, São Francisco. Não é necessário discutir o quão importantes são esses rios para o Brasil, rios cuja dimensão e grandeza estão nos aspectos culturais, históricos, econômicos e sociais da vida do ovo brasileiro. Porém, o avanço sobre o Cerrado produziria consequências devastadoras especialmente para o Pantanal.

As políticas agrícolas gerais e de desenvolvimento regional tiveram fundamental importância na expansão agrícola nos cerrados. Dentre as políticas gerais, citam-se a quase total isenção de imposto de renda, os subsídios ao crédito rural, em um período, e a politica de preços mínimos, em outro. A quase isenção de imposto de renda foi uma compensação à tributação indireta e ao controle de preços de produtos agrícolas à época da inflação alta. As políticas de desenvolvimento regional tiveram impacto direto sobre certas áreas do cerrado. Como instrumentos de desenvolvimento regional, ha os programas especiais para regiões especificas e os projetos de colonização pública e privada. Introduzindo melhorias de infraestrutura e tonificação, tiveram reflexo favorável sobre a produção agrícola. Como exemplo de politica de desenvolvimento regional pode-se citar o POLOCENTRO. (JESUS, 1988, p. 32). 
A ditadura civil-militar ficou marcada do ponto de vista legislativo, não sem motivo, pelos Atos Institucionais - AI que em regra foram utilizados como instrumento de legalização, legitimação, daquilo que foi um dos piores períodos de nossa história, ou seja, a ditadura. Porém, como já dissemos anteriormente o estado de exceção não se restringe a apenas um aspecto do direito, mas a todo o ordenamento jurídico. Apesar de não ser um ato institucional o estado de exceção ambiental pode ser percebido no Brasil pelo Decreto $n^{0} 75.320 / 1975^{1}$ que dispôs sobre a criação do Programa de Desenvolvimento dos Cerrados (POLOCENTRO).

1 DECRETO $\mathbf{N}^{0}$ 75.320, DE 29 DE JANEIRO DE 1975. Dispõe sobre a criação do Programa de Desenvolvimento dos Cerrados (POLOCENTRO). O PRESIDENTE DA REPÚBLICA, no uso das atribuições que lhe confere o artigo 81, item III, da Constituição,

DECRETA:

Art. $1^{\circ}$. É criado o Programa de Desenvolvimento dos Cerrados (POLOCENTRO), com o objetivo de promover o desenvolvimento e a modernização das atividades agropecuárias no Centro-Oeste e no Oeste do Estado de Minas Gerais, mediante a ocupação racional de áreas selecionadas, com características de cerrado.

Art. $2^{\circ}$. São as seguintes as áreas preliminarmente selecionadas com vista à execução do Programa: 1 Estado de Minas Gerais: Triângulo Mineiro (ao longo da BR-365, entre Patrocínio e Canápolis); Alto-Médio São Francisco (limitada pelos rios Paraopeba, São Francisco e das Velhas, de Sete Lagoas até Pirapora) e Vão do Paracatu (localizada entre cidade de Paracatu e a BR-356, tendo como eixo a BR-040; II - Estado de Mato Grosso: Campo Grande-Três Lagoas (ao longo da Estrada de Ferro Noroeste, entre Campo Grande e Três Lagoas); Bodoquena (ao longo da rodovia de ligação entre Aquidauana e Bonito); Xavantina (delimitada pelo rio Cristalino e ribeirão Água Preta) e Parecis (localizada ao longo da BR-364,entre os ribeirões Sumidouro e Sacré); III - Estado de Goiás: Gurupi (ao longo da BR-153, entre as localidades de Gurupi e Porangatu); Paraná (ao longo da BR-020, entre o rio Paraim e a cidade de Posse); Pirineus (ao longo da BR-080, entre a divisa do Distrito Federal com Goiás e do rio das Almas); Piranhas (ao longo da BR-158, entre Piranhas e Aragarças) e Rio Verde (localizada entre os rios Verde Grande e Claro e o eixo da BR-060).

Art. $3^{\circ}$. O Programa de Desenvolvimento dos Cerrados (POLOCENTRO) terá, nos exercícios de 1975 a 1977, recursos no valor de, no mínimo, Cr\$2.000.000.000,00 (dois bilhões de cruzeiros), a preços de 1975, do modo seguinte:

I - Cr\$ 700.000.000,00 (setecentos milhões de cruzeiros) no exercício de 1975, provenientes das seguintes fontes; Cr\$260.000.000,00 (duzentos e sessenta milhões de cruzeiros) do Fundo de Desenvolvimento de Áreas Estratégicas - FDAE; Cr\$200.000.000,00 (duzentos milhões de cruzeiros) do Fundo de Desenvolvimento de Programas Integrados - FDPI; Cr\$ 40.000.000,00 (quarenta milhões de cruzeiros) de recursos orçamentários do Ministério da Agricultura; e Cr\$200.000.000,00 (duzentos milhões de cruzeiros) através de financiamentos internos;

II - Cr\$ 650.000.000,00 (seiscentos e cinquenta milhões de cruzeiros), a serem incorporados na proposta orçamentária para o exercício de 1976;

III - Cr\$ 650.000.000,00 (seiscentos e cinquenta milhões de cruzeiros), a serem incorporados na proposta orçamentária para o exercício de 1977.

Art. $4^{\circ}$. O Programa de Desenvolvimento dos Cerrados (POLOCENTRO) será implementado pelos Ministérios do Interior, da Agricultura e da Fazenda, assim como pelos demais Ministérios e agentes financeiros envolvidos, em articulação com os Governos dos Estados de Minas Gerais, Mato Grosso e Goiás. Parágrafo único. A Secretaria de Planejamento manterá esquema de coordenação das providências a serem adotadas e do acompanhamento da execução do Programa, em Articulação com os Ministérios do Interior e da Agricultura.

Art. $5^{\circ}$. Os diversos órgãos envolvidos no Programa, sob a coordenação da Secretaria de Planejamento, promoverão a sua pormenorização, inclusive no tocante ao apoio financeiro.

Art. $\mathbf{6}^{\mathbf{0}}$. Este Decreto entrará em vigor na data de sua publicação, revogadas as disposições em contrário. Brasília, 29 de janeiro de 1975; $154^{\circ}$ da Independência e $87^{\circ}$ da República.

\section{ERNESTO GEISEL}

Mário Henrique Simonsen

Paulo Afonso Romano

Dyrceu Araújo Nogueira

Severo Fagundes Gomes 
Dessa maneira, o Programa de Desenvolvimento dos Cerrados conhecido como POLOCENTRO é a representação legal daquilo que não pode ter forma legal, no caso o avanço sobre a natureza no intuito de promover acúmulo sem qualquer mensuração das consequências e com destruição de tudo que se opusesse ao processo de Raubbau capitalista no Cerrado (FOSTER, 2011).

Em complemento é importante trazer um apanhado das políticas e ações da ditadura civil-militar para o centro-oeste especialmente no Mato Grosso, lembrando que o estado de Mato Grosso foi desmembrado para a criação do Estado de Mato Grosso do Sul, logo antes da divisão tratava-se de do mesmo território. Dito isso cite-se:

Para a implementação da efetiva ocupação das áreas sub-povoadas, o Estado teve o papel de preparar essas áreas para receber as novas dinâmicas, nacionais e mundiais, através dos programas de desenvolvimento regional. Esses programas foram demandados dentro de um planejamento a partir das particularidades regionais. Um dos aspectos que pode ser observado a partir da pesquisa sobre o avanço agronegócio sojífero no Estado de Mato Grosso, foi a densidade de políticas públicas delegadas através de vários planos e programas de desenvolvimento regional, sobretudo, a partir da segunda metade do século XX. No início da década de 70 do século XX, acentuouse mais ainda o interesse pela ocupação das áreas de fronteira, em razão do que, novas políticas foram investidas visando efetivar o processo e consequentemente aumentar a produção de exportação. Assim, o Governo Federal, lançou novos Programas e planos de incentivos vinculados a SUDECO e SUDAM e associados ao Plano Nacional de Desenvolvimento - PND, I e II. No âmbito das superintendências regionais os programas de abrangência regional, remetam novos ordenamentos ao território mato-grossense através dos recursos injetados para o desenvolvimento regional, como o programa de integração nacional - PIN, "[...] o mais importante instrumento de integração da Amazônia as regiões mais "desenvolvidas" do país". Moreno (2005, p. 39). O Programa de integração nacional - PIN, criado em 16 de junho de 1970, Tinha como objetivo financiar obras de infra-estrutura, como a abertura de rodovias federais e outras ações. No entanto, no Mato grosso, o tom do programa foi dado na implantação de importantes rodovias federais para $o$ escoamento da produção agropecuária atual, são elas: BR-163, trecho CuiabáSantarém; BR-364, trecho Cuiabá-Porto Velho; BR-070, trecho Rio AraguaiaCuiabá; BR-080, trecho Rio Araguaia - Cachimbo; BR-158, trecho Barra do Garças São Felix do Araguaia; e a BR-174, trecho de Cáceres a fronteira com Rondônia. Programa de Redistribuição de terras e Estímulo a Agroindústria -PROTERRA, instituído em 6/07/1971, objetivou dar oportunidade ao pequeno produtor para adquirir sua propriedade de terra, e assim ampliar a produção de alimentos, fibras, forrageiras e animais. - Corredores de exportação - COREXPORT, criado em 04 de novembro de 1971, este objetivava diversificar e aumentar as exportações de produtos agropecuários. Baseado em dois pilares fundamentais, aumentar a exportação e viabilizar seu escoamento. - Programa de Desenvolvimento do Centro-Oeste PRODOESTE, implantado em 8/12/1971, voltado ao estímulo da produção, tendo priorizado como medida de apoio aos seus objetivos, a construção de estradas de interiorização que permitissem o escoamento da produção até os principais centros de comercialização, consumo, industrialização e exportação. Este programa viabilizou, também, obras de infra-estrutura rural, como a instalação de frigoríficos, expansão de unidades de armazenamentos, saneamento e de eletrificação. (GATTI, NUNES, SOBRINHO, 2020, sp).

João Paulo dos Reis Velloso Maurício Rangel Reis. 
Percebemos com tais políticas que o estado de exceção por intermédio de tais ações, como o Decreto $n^{\circ} 75.320 / 1975$, se volta para o seu espaço interno, no caso o bioma Cerrado, e sobre ele busca justificar e legitimar a destruição da vida existente neste espaço, sempre visando o acúmulo. Como acreditar que esse processo seria benéfico? Em essência nunca será, mas no mundo do dever ser essa destruição poderia ser vista como benéfica.

No período 1975-82, 3.373 projetos foram aprovados pelo POLOCENTRO, somando recursos equivalentes a 631,3 milhões de dólares, a preços de junho de 1984. Nas áreas menores de 100 ha, encontravam-se $2,2 \%$ do número total de projetos, respondendo por $0,3 \%$ dos recursos de crédito liberados. No extrato de 100 a menos de 500 ha, encontravam-se $30,5 \%$ do número de projetos, respondendo por $13,8 \%$ dos recursos. No extrato de 500 a menos de 1.000 ha, encontravam-se 19,2\% do número de projetos, com 15,2\% dos recursos. No extrato de mais de 1.000 ha, encontravamse $38,8 \%$ do número de projetos, com $61,3 \%$ dos recursos. Finalmente, ha os projetos sem declaração de área, com $9,4 \%$ do número de projetos e mesmo percentual dos recursos liberados. As pequenas propriedades, consideradas até 100 ha, tiveram participação marginal no número de projetos e menor ainda na captação de recursos. As grandes propriedades, consideradas acima de 500 ha, com $58 \%$ do número de projetos, absorveram $76,5 \%$ dos recursos. O crédito público subsidiado foi usado em beneficio dos maiores proprietários, justamente os mais capitalizados. Os recursos públicos subsidiados do programa beneficiaram a concentração de renda no campo, em detrimento da pequena propriedade de cunho familiar. (JESUS, 1988, p. 40/41).

Acúmulo para os grandes proprietários de terras em detrimento das pequenas propriedades, geralmente de agricultura familiar, além do incentivo via discurso o governo rompe com a legalidade quando estimula com recursos públicos a destruição da natureza. Não há outra definição, ou seja, dentro do modelo agrário de produção extensiva a alteração do bioma é feita de modo violento e fundado na destruição da fauna e flora.

Neste sentido, para que se entenda o porquê dessa simbiose entre estado de exceção e direito é preciso entender a propriedade e como ela é fundamento da sociedade capitalista e, por consequência do Estado e do Direito. O termo propriedade se refere à característica particular de algo, ou de alguém, por exemplo, a adstringência é uma propriedade dos vinhos feitos com uvas Cabernet Sauvignon, ou seja, a propriedade é característica distintiva de algo ou alguém.

É importante fazer um questionamento: Seria possível que ocorresse uma cessão/transmissão de propriedade sem que transmissor e o receptor perdessem suas essências? Entendemos que não, pois o que é próprio está contido e não será incorporado, ou seja, entendendo que essência é o objetivo de algo, qualquer ato cessão/transmissão fatalmente alterará essa essência, pois trata-se do ato de apropriar algo ou alguém de uma propriedade que não é sua, ou de algo que não lhe é próprio.

Se o ato descrito de apropriar algo ou alguém de uma característica externa (que não lhe pertence) altera a essência deste que esta recebendo essa característica, o processo reverso 
de desapropriar também altera a essência daquele de quem se desapropria. De modo que apropriar ou desapropriar somente é possível em um mundo virtual, pois no mundo real as coisas são, ou seja, o antônimo do que deveriam ser.

Ocorre, que essa propriedade como expressão da pessoa não é uma condição alcançada por todos, ou seja, nem todos os humanos serão bem aventurados neste processo e isso fará fatalmente com que aqueles que se alçam a condição de proprietário iniciem a dominação dos demais por meio da propriedade que é entendida como a externalização do indivíduo.

Dessa maneira, a propriedade passa a ser elemento diferenciador entre um indivíduo e outro e, justamente por isso é posta no centro deste processo de dominação do proprietário sobre o não proprietário. Daí chega-se a um ponto crucial que é justamente o de que o Estado surge para proteger a propriedade que é entendida como a expressão externa da pessoa, no caso, do proprietário.

Logo, pode-se concluir que o Estado protege uma exceção que é a propriedade, pois como já analisado a propriedade é elemento extrínseco do ser humano, elemento este que não é alcançado por todos. E essa proteção estatal é feita pelo ordenamento jurídico, ou seja, o direito, a lei, e demais formas de regulamentos, enfim pelo mundo do dever ser. Portanto, sem a propriedade não haveria necessidade de direito, ou melhor, talvez o direito sequer tivesse surgido nesta forma conhecida atualmente.

Feita essa ponderação é importante uma análise em torno da expressão Estado de exceção, ou seja, lançou-se a ideia de que o Estado se funda em uma exceção que é a propriedade e, por conseguinte as expressões de Estado e exceção apresentam uma similitude bastante consistente.

Neste sentido, frequentes são as análises e discussões em torno do Estado de Exceção, seu surgimento não é recente, mas talvez o seu conceito é que tenha sido aprimorado, ou se desenvolvido de modo mais claro atualmente.

Daí uma questão central. Se a propriedade é algo escasso como pode algo que surgiu da propriedade ser abundante? É refletir sobre o fato de que o direito é exceção porque surge de uma exceção, qual? A propriedade. Logo, o direito assim como sua fonte (a propriedade) não poderia ser outra coisa que não uma exceção por natureza.

Em essência o direito é escasso, mas devido a uma construção histórica o homem irá interpretá-lo de dois modos: o primeiro deles é como liberdade para os proprietários, e o segundo é como ordem de negação, uma espécie de obrigação de não fazer, para os não proprietários. 
Interessante é analisar que Estado e Direito também se criam e se complementam na medida em que o direito produzido pelo Estado serve de justificação para o poder estatal e ao mesmo tempo em que regulamenta a relação entre os proprietários e os despossuídos. Nesse sentido, chega-se a uma reflexão de que Estado e Direito se fundem, constroem-se mutuamente, logo, o termo Estado de direito é em essência Estado de exceção uma vez que o direito surge da propriedade e o Estado surge para proteger essa propriedade.

Após do delineamento desse raciocínio cite-se Giorgio Agamben "O estado de exceção fica no limite entre a política e o direito. Estar no limite entre a política e o direito entende-se aqui como um lugar, ou posição, de algo que esteja entre o mundo real representado pela política (ser) e o mundo virtual representado pelo direito (dever ser). Logo, o estado de exceção apresenta-se como a forma legal do que não pode ter forma legal”. (AGAMBEN, 2004, p. 11/12).

O estado de exceção volta-se para o espaço interno do Estado, para seus elementos constituidores povo, território e poder. E é o que se define como guerra civil legal. Cite-se Adolf Hitler que promulgou o "Decreto para a proteção do povo e do Estado" que suspendeu direitos relativos às liberdades

O decreto nunca foi revogado, de modo que todo o Terceiro Reich pode ser
considerado, do ponto de vista jurídico, como um estado de exceção que durou doze
anos. O totalitarismo moderno pode ser definido, nesse sentido, como a instauração,
por meio do estado de exceção, de uma guerra civil legal que permite a eliminação
física não só dos adversários políticos, mas também de categorias inteiras de cidadãos
que, por qualquer razão, pareçam não integráveis ao sistema político. Desde então, a
criação voluntária de um estado de emergência permanente (ainda que,
eventualmente, não declarado no sentido técnico) tornou-se uma das práticas
essenciais dos Estados contemporâneos, inclusive dos chamados democráticos.
Diante do incessante avanço do que foi definido como uma "guerra civil mundial", o
estado de exceção tende cada vez mais a se apresentar como o paradigma de governo
dominante na política contemporânea. Esse deslocamento de uma medida provisória
e excepcional para uma técnica de governo ameaça transformar radicalmente -e, de
fato, já transformou de modo muito perceptível - a estrutura e o sentido da distinção
tradicional entre os diversos tipos de constituição. O estado de exceção apresenta-se
nessa perspectiva, como um patamar de indeterminação entre democracia e
absolutismo. (AGAMBEN, 2004. p. 12/13).

Percebe-se que o autor se empenha em estabelecer que o estado de exceção situa-se em um limbo, um espaço entre o direito e a política, ou entre a democracia e o absolutismo. Porém, confirmar esse raciocínio nada mais é que raciocinar para compreender a expressão “dar forma legal ao que não tem forma legal".

Veja que a ditadura civil-militar apesar de ser um absurdo sempre se estruturou no direito, ou seja, seja por atos institucionais, seja por decretos, o fato é que a ditadura civil-militar no Brasil foi um estado de direito em sua compreensão formal. Sendo assim Alysson Leandro 
Mascaro apresenta uma compreensão do que seja esse quadro político e econômico no qual o direito está inserido. Vejamos:

Todo direito é um golpe. É a forma do engendramento da exploração do capital e da correspondente dominação de seres humanos sobre seres humanos. Tal golpismo jurídico se faz mediante instituições estatais, sustentando-se numa ideologia jurídica que é espelho da própria ideologia capitalista. Sendo o direito sempre golpe, a legalidade é uma moldura para a reprodução do capital e para a miríade de opressões que constituem a sociabilidade. Todo o direito e toda a política se fazem a partir de graus variados de composição entre regra e exceção. (MASCARO, 2020, sp).

Imaginemos o rol de direitos que se conhece, mas que nunca saíram do plano ideal/formal. A população foi alienada ao ponto de acreditar que formalizar direitos é garantia de que efetivamente se gozará desses direitos. Neste sentido, a construção em torno de regra e exceção consegue explicar de modo explícito o golpismo do direito positivo, por exemplo. Neste sentido o papel do Poder Judiciário é justificar a regra ou a exceção conforme o momento.

O direito é forma social capitalista. Sua materialidade se funda nas relações entre portadores de mercadorias que se equivalem juridicamente na troca. A forma jurídica é constituinte da sociabilidade capitalista. $\mathrm{O}$ mesmo quanto à forma política estatal, terceira necessária em face dos agentes da exploração capitalista. O Estado, mesmo quando governado por agentes e classes não-burguesas, é capitalista pela forma. (MASCARO, 2020, sp).

O Estado é capitalista pela forma. Esta afirmação diz muito, ou quase tudo, para a compreensão da ideia proposta neste texto, pois a ditadura civil-militar brasileira é fruto de articulação do capitalismo, os militares brasileiros foram guiados pela logica capitalista, que por sua vez trabalha com propriedade que é garantida pelo direito e pela legislação. Explica-se:

\begin{abstract}
A vitória das leis sobre o arbítrio dos homens acompanhou a vitória do capitalismo sobre as formas econômicas que lhe eram anteriores. A liberdade dentro das leis, princípio da legalidade, era irmã da liberdade no mercado, no qual se compra ou se vende a partir da própria vontade. A igualdade formal, que serviu de lema das revoluções liberais, é o espelho de um mundo feito um grande mercado, no qual todos se igualam na condição de compradores e de vendedores, no qual até a exploração deixa de ser um mando direto de um senhor sobre um escravo e passa a ser a igual vontade jurídica de patrão e proletário. A vitória da legalidade é a vitória de um mundo feito grande mercado. Por mais diversos sejam os homens, por mais egoístas seus interesses, todos num passe de mágica são formalmente iguais aos outros, exploradores e explorados, e, perante a imparcialidade da lei, a igualdade e a vontade sem coerção cobrem todos os atos jurídicos com o manto da justiça formal. (MASCARO, 2003, p. 22/23).
\end{abstract}

Uma das consequências nefastas da legalidade, dentre várias, é que a legalidade restringe, delimita, o espaço para a discussão e consequentemente para a luta do povo. E isso só ocorre porque criados os direitos o povo automaticamente vira os olhos para a lei e se desconecta da realidade concreta, ou seja, sem atenção não vê que a leis não são cumpridas quando isso pode confrontar interesses da classe dominante.

Classe dominante que foi capaz de idealizar o golpe de 1964, com apoio dos Estados 
Unidos, e deixar a execução por conta das forças armadas que uma vez no governo foram decisivas para a política de marcha sobre o Cerrado do Brasil.

\section{O Pantanal na Ditadura Civil-militar}

A poesia não pede passagem para a ciência, pelo contrário, a ciência implora pela poesia para que não se torne esvaziada de sentido para a vida humana no planeta. Neste sentido:

O Rio Taquari

Plante que o "João garante",

Era a bravata de então...

Estávamos no "inferno de Dante"...

Ame-o ou deixe-o, Brasil Tri-Campeão...

Sem critérios, com consentimento

Retiraram as matas ciliares, fizeram desmatamento...

Teve início uma tragédia, sem alarido

O Rio Taquari começou a ser destruído...

Acadêmicos do Pantanal em protesto,

Tentaram fazer um manifesto

Não deu outra, foram vistos como loucos,

Afinal de contas, eram tão poucos...

Mas a areia do planalto desceu, fechando o canal

Os menos avisados acharam que era normal...

Era, para eles, mais uma grande cheia no Pantanal...

Mal sabiam eles, agora era de fato: fatal...

Morreram bois, sumiram fazendas, casas foram deixadas

As plantações foram destruídas e abandonadas...

A traia era arrumada, irmão socorria irmão

O velho caboclo do Taquari partia, com dor no coração...

Agora, a água da enchente-perene, não cria peixe e nem boi

A esperança do pantaneiro com o vento se foi...

Resta uma pequena esperança, viva no coração

Pesquisadores, cientistas, povo e governo acharem uma solução...

Triste, não é apenas a cena da boa novela,

Triste é ver o caboclo do Taquari, vivendo na favela...

Passando até a dura humilhação e tristeza.

Por um pouco de feijão em sua panela...

(MANOEL VITÓRIO, apud GALDINO, 2006, p. 14)

Apesar de não muito rotineiro em textos jurídicos a citação de um poema visa imitar o próprio Rio Taquari que leva a água ao Pantanal brasileiro irriga-o, dá-lhe vida. Assim é o poema que leva a poesia que irriga a alma humana. Porém, a grandeza da poesia acima descrita também nos dá a dimensão do objeto do presente trabalho, ou seja, analisar os impactos que um estado de exceção pode produzir sobre um ecossistema. Portanto, é importante pontuar que 
é preciso fortalecer uma compreensão do estado de exceção que extrapole a dimensão restrita ao campo bélico/militar/penal, ou seja, ele está em todos os campos da vida.

Dito isso apresentamos um dado importante trazido por Caio Prado Junior onde apresenta dados do Instituto Brasileiro de Reforma Agrária, referentes ao ano de 1967, no tocante ao crescimento das áreas de lavoura e pastagens para a pecuária:

\begin{tabular}{|c|c|c|c|c|c|c|}
\hline Fonte no Rodapé & 1940 & \multicolumn{2}{|l|}{1950} & 1960 & 1967 & \\
\hline $\begin{array}{l}\text { Lavouras (h.) \% de } \\
\text { aumento }\end{array}$ & $18.885 .430-$ & $\begin{array}{l}19.095 .057 \\
1,0 \%\end{array}$ & - & $\begin{array}{l}29.759 .784- \\
55,7 \%\end{array}$ & $\begin{array}{l}37.212 .692- \\
24,9 \%\end{array}$ & \\
\hline $\begin{array}{l}\text { Pastagens (h.) e \% } \\
\text { de aumento }\end{array}$ & $88.141 .733-$ & $\begin{array}{l}107.547 .262 \\
22 \%\end{array}$ & - & - & $\begin{array}{l}122.670 .251 \\
14 \%\end{array}$ & - \\
\hline 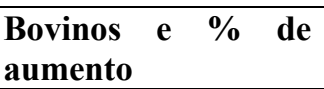 & $44.600 .000-$ & $\begin{array}{l}46.891 .208 \\
4,9 \%\end{array}$ & - & $\begin{array}{l}\mathbf{5 5 . 6 9 2 . 6 5 3} \\
18,7 \%\end{array}$ & $\begin{array}{l}\text { 90.153.000 } \\
61,8 \%\end{array}$ & - \\
\hline
\end{tabular}

O particularmente notável nestes dados é o considerável aumento da pecuária, em que se compreende tanto o gado vacum de corte, como o leiteiro - este último concentrado sobretudo no leste de São Paulo, oeste do Rio de Janeiro e sul de Minas Gerais. Esse crescimento da pecuária se explica essencialmente pelo aumento do consumo de carne, do leite e seus derivados, nos grandes centros urbanos do centro leste, em particular São Paulo e Rio de Janeiro (Guanabara). Entre 1940 e 1967, as pastagens aumentam de quase 35 milhões de hectares, e o rebanho bovino mais que dobrou. Em parte, a considerável expansão das pastagens se fez em terras antes desocupadas, como em certas regiões pioneiras de São Paulo, Goiás e Mato Grosso, onde aliás a expansão prossegue em ritmo acelerado, correspondendo às perspectivas de intensificação das explorações de carne. (PRADO JUNIOR, 1985, p. 337).

Os dados apresentados demonstram que a partir dos anos de 1960 ocorreu intensificação da atividade agropecuária no Brasil. Dada a característica da atividade agropecuária esse processo de expansão teve como destino as áreas de terras distantes dos grandes centros para abastecê-los com produtos, então, o Centro-Oeste brasileiro foi um dos destinos da chegada, fixação e expansão do agronegócio neste período.

Neste sentido, é importante citar que na Região Centro-Oeste formada pelos estados de Mato Grosso do Sul, Goiás e Mato Grosso, situa-se a maior planície alagável do mundo o Pantanal brasileiro, especificamente nos estados de Mato Grosso do Sul, onde se localiza a maior parte do ecossistema pantaneiro, e Mato Grosso.

O Pantanal é uma planície sedimentar com superfície de 147.574 km (Brasil, 2004). Está inserido na Bacia do Alto Paraguai (BAP), que se localiza no oeste do Brasil (...). A BAP em território nacional possui uma superfície de $362.376 \mathrm{~km}$ (Brasil, 2004) que, além da Planície Pantaneira, compreende também planaltos adjacentes, com área de $214.802 \mathrm{~km}$. Nesses planaltos, com altitudes superiores a $200 \mathrm{~m}$, estão as nascentes dos rios pantaneiros. O Rio Taquari é um dos principais formadores do Pantanal (...). Ao adentrar a Planície Pantaneira no pleistoceno, em condições climáticas diferentes das atuais, quando os agentes deposicionais na área apresentavam extrema energia do tipo torrencial, o Rio Taquari formou um gigantesco leque aluvial de $55.509 \mathrm{~km}$, onde situam-se as duas principais sub-regiões do Pantanal, o Paiaguás e a Nhecolândia (Brasil, 1982). Esse leque aluvial é um dos maiores do mundo e representa $36 \%$ da área do Pantanal. (GALDINO, 2006, p. 29). 
A importância e grandeza do Pantanal não se demonstram apenas por sua extensão e riquezas naturais, pois devido a esta sua característica o legislador constituinte lançou o equilíbrio e proteção do Pantanal como direito fundamental, na medida em que goza de proteção constitucional quando o texto da Constituição Federal dispôs de modo direto:

Art. 225. Todos têm direito ao meio ambiente ecologicamente equilibrado, bem de uso comum do povo e essencial à sadia qualidade de vida, impondo-se ao Poder Público e à coletividade o dever de defendê-lo e preservá- lo para as presentes e futuras gerações.

$\S 1^{\circ}$ Para assegurar a efetividade desse direito, incumbe ao Poder Público: I - preservar e restaurar os processos ecológicos essenciais e prover o manejo ecológico das espécies e ecossistemas; II - preservar a diversidade e a integridade do patrimônio genético do País e fiscalizar as entidades dedicadas à pesquisa e manipulação de material genético; III - definir, em todas as unidades da Federação, espaços territoriais e seus componentes a serem especialmente protegidos, sendo a alteração e a supressão permitidas somente através de lei, vedada qualquer utilização que comprometa a integridade dos atributos que justifiquem sua proteção; IV - exigir, na forma da lei, para instalação de obra ou atividade potencialmente causadora de significativa degradação do meio ambiente, estudo prévio de impacto ambiental, a que se dará publicidade; V - controlar a produção, a comercialização e o emprego de técnicas, métodos e substâncias que comportem risco para a vida, a qualidade de vida e o meio ambiente; VI - promover a educação ambiental em todos os níveis de ensino e a conscientização pública para a preservação do meio ambiente; VII - proteger a fauna e a flora, vedadas, na forma da lei, as práticas que coloquem em risco sua função ecológica, provoquem a extinção de espécies ou submetam os animais a crueldade.

$\S 2^{\circ}$ Aquele que explorar recursos minerais fica obrigado a recuperar o meio ambiente degradado, de acordo com solução técnica exigida pelo órgão público competente, na forma da lei.

$\S 3^{\circ}$ As condutas e atividades consideradas lesivas ao meio ambiente sujeitarão os infratores, pessoas físicas ou jurídicas, a sanções penais e administrativas, independentemente da obrigação de reparar os danos causados.

$\S 4^{\circ}$ A Floresta Amazônica brasileira, a Mata Atlântica, a Serra do Mar, o Pantanal Mato-Grossense e a Zona Costeira são patrimônio nacional, e sua utilização farse-á, na forma da lei, dentro de condições que assegurem a preservação do meio ambiente, inclusive quanto ao uso dos recursos naturais. (Grifei).

Aí é possível perceber qual foi o tratamento dado pelo constituinte ao meio ambiente no que se refere ao lançamento de importantes bases para uma política pública do Estado brasileiro para os ecossistemas encontrados no Brasil. Porém, talvez essas bases constitucionais tenham sido idealizadas um tanto tarde, pois a Constituição Federal de 1988 reflete um período em que a ditadura civil-militar estava no fim, ou seja, eventuais impactos e destruição ecológica já teriam ocorrido de 1964 até 1988.

Dito isso, retomamos ao detalhamento do ecossistema pantaneiro. Conforme citado anteriormente o Rio Taquari é um dos principais formadores do Pantanal, pois a bacia do rio responde por $36 \%$ da área diretamente responsável pela pujança do ciclo ecológico pantaneiro fundado na alternância entre secas e cheias que condicionam a vida neste ecossistema.

Essa característica cíclica do ecossistema pantaneiro destaca a importância estratégica da Bacia do Rio Taquari para o ciclo de vida no Pantanal. O Rio Taquari nasce no planalto e 
flui até o seu encontro com o Rio Paraguai já em território da planície pantaneira. De sua nascente (entre a Serra da Saudade e a Serra de Maracaju) até a foz o Rio Taquari possui 801 km de extensão. A Bacia do Alto Taquari possui grande importância biológica para o Pantanal. Essa bacia pode ser dividida em três partes diferentes,

\begin{abstract}
O primeiro compartimento representa a Bacia do Alto Taquari (BAT), com superfície aproximada de $28.000 \mathrm{~km}$, que compreende a área do planalto drenado pelo Rio Taquari e seus afluentes até a escarpa cuestiforme da Bacia Sedimentar do Paraná, próxima à Cidade de Coxim. É caracterizado por uma rede de drenagem com alto poder de erosão e transporte de sedimento. O segundo compartimento, denominado de Médio Taquari, inicia-se nas proximidades da Cidade de Coxim, quando o rio rompe o obstáculo formado pelos sedimentos da Bacia do Paraná, penetrando na Planície Pantaneira, e termina próximo à fazenda São Gonçalo. Nesse segundo compartimento o Rio Taquari meandra dentro de uma planície de inundação restrita, apresenta uma calha de sedimentação bem definida e retrabalha os sedimentos depositados, sendo caracterizado pela erosão das margens localizadas na parte côncava e deposição na parte convexa. O terceiro compartimento, conhecido por Baixo Taquari inicia-se próximo à fazenda São Gonçalo e termina no Rio Paraguai. Neste trecho o Rio Taquari perde o seu poder de erosão e transporte de sedimento, passando a delinear uma ampla faixa de depósitos aluviais que se alarga, à jusante, como um delta. (GALDINO, 2006, p. 31).
\end{abstract}

O Pantanal é uma planície com características biológicas distintas das encontradas no Cerrado do Brasil, porém na descrição destas três partes da Bacia do Alto Taquari percebe-se que é justamente no Cerrado que está a fonte do Rio Taquari e é de onde a água levada pelo rio é drenada do planalto para irrigar o ciclo das cheias no Pantanal. Logo, existe uma simbiose entre Cerrado e Pantanal apesar de possuírem características biológicas diferentes.

O sistema biológico pantaneiro possui um regime de inundações que se caracterizam pelas variações sazonais e pela alternância de períodos plurianuais de seca e de cheia este é o ciclo natural do referido ecossistema. A alteração deste ciclo promoverá risco para a vida na região.

Sendo assim, qual seria o papel do Estado nestes processos? Não se diga que o papel estatal é o que está disposto do Art. 225 da Constituição Federal, afinal essa ideia de proteção ambiental como política pública do Estado surgiu posteriormente a ditadura civil-militar. $\mathrm{O}$ papel do Estado foi suspender o ordenamento jurídico de proteção ambiental estimulando violentamente o avanço do agronegócio sobre o Centro-Oeste:

Em 1977 as lavouras e as pastagens cultivadas ocupavam apenas 3,4\% da Bacia do Alto Taquari (Oliveira et al., 1997). Nessa época, após o desmatamento, cultivava-se arroz por 2 ou 3 anos e, posteriormente, formava-se pastagens nessas áreas (Brasil, 1982). Mais recentemente, em 2000, as áreas ocupadas pela agropecuária correspondiam a $61,9 \%$ da superfície da BAT (Silva, 2003), ou seja, em apenas 26 anos as áreas utilizadas pela agropecuária aumentaram em $1.820 \%$. Essa rápida expansão da agropecuária na BAT, principalmente das culturas de soja e milho, as quais demandam a utilização de biocidas em larga escala, constitui uma ameaça ao bioma Pantanal pela alteração da biodiversidade como reflexo das modificações decorrentes na estrutura dos ecossistemas (Vieira et al., 2001). Apesar da produção de sedimentos na BAT e a consequente deposição de sedimento pelo Rio Taquari na sua 
planície de inundação ser um fenômeno natural, esse processo foi intensificado com a expansão desordenada da atividade agropecuária na alta bacia. As pastagens cultivadas, em 2000, ocupavam 54,8\% das terras da BAT (Silva, 2003). Essas áreas são as mais castigadas pela erosão devido ao uso inadequado do solo, desmatamentos indiscriminado nas encostas e nos topos dos morros e predomínio de solos de textura arenosa de baixa fertilidade (Brasil, 1997). A quase totalidade das áreas de pastagem cultivadas localizadas na BAT são mal manejadas e não adotam práticas conservacionistas de solo. A consequência imediata é a intensificação da erosão laminar, devido a maior exposição do solo à ação da chuva (Fig. 6). (GALDINO, 2006, p. 36)

Partindo do pressuposto de que ao Estado foi incumbida a missão de proteger o cidadão é imprescindível que políticas de preservação sejam traçadas porque os exemplos mostram que com relação a natureza os danos podem ser irreversíveis, ou seja, "quem paga pra ver" não consegue reparar os eventuais danos e impactos gerados.

Refletindo sobre o trecho citado é possível perceber que a exploração ocorreu de maneira abrupta e consequentemente a alteração do bioma também sofreu impactos de modo vultuoso e acelerado, ou seja, "em apenas 26 anos as áreas utilizadas pela agropecuária aumentaram em 1.820\% (GALDINO, 2006, p. 36)". Como dizer que um crescimento de $1.820 \%$ não gera efeitos graves de imediato e futuramente? Logicamente o ecossistema não está preparado para uma mudança dessa monta.

\subsection{A destruição explícita}

Como vimos o Pantanal passou por um processo de expansão da atividade agropecuária/agronegócio, ocorre que essa expansão aliada a práticas arcaicas de cultivo gera destruição, além disso a expansão da área sem proteção do meio ambiente transformará a área expandida uma área improdutiva.

Os processos erosivos na BAT vêm causando sérios prejuízos econômicos para a pecuária da região, devido principalmente, à perda de área para a alimentação dos bovinos e à diminuição da produtividade das pastagens decorrente da redução, ainda maior, da fertilidade dos solos. Além da questão econômica, a degradação ambiental é bastante visível. É frequente encontrar áreas de pastagens cultivadas em locais onde deveriam existir matas ciliares (...) e a quase totalidade dos cursos d'água, à jusante das áreas de pastagens em solos arenosos, apresentam bancos de areia ou estão totalmente assoreados (...). (GALDINO, 2006, p. 37).

A exploração sem os devidos cuidados com o ecossistema é uma característica do pensamento tacanho que conduz o agronegócio em países governados por quem não tem o menor compromisso com a humanidade. Constata-se então, que de fato a condução dos Estados depende de como a governo se comunica com a população, pois o povo em sua maioria tende a avançar sobre espaços abertos pelo discurso dos governantes, portanto, quando um governo 
não tem a proteção ambiental em sua plataforma dificilmente o povo terá, especialmente em países de capitalismo tardio e dependente como o Brasil.

O meio ambiente em países de capitalismo tardio e dependente costuma ser visto como um conjunto inesgotável de matéria prima cuja exploração desenfreada é fundamental para que se tenha êxito no processo de desenvolvimento. Em momento algum dessa exploração se percebe o óbvio da questão ambiental, ou seja, os danos jamais, e é jamais, serão revertidos, pelo contrário, serão agravados. Essa forma primária e simplista de pensamento fez com que o assoreamento da Bacia do Alto Taquari aumentasse a descarga de sedimentos no leito do rio:

A intensificação dos processos erosivos na BAT pode ser constatada pelo aumento da descarga sólida total (arraste e suspensão) no Rio Taquari, em Coxim. Entre os períodos de 1977/1982 e 1994/1995, o aporte de sedimentos provenientes da BAT para o Pantanal, saltou de 20.224 para $29.243 \mathrm{t}$ dia , ou seja, houve um incremento de 44,6\% (Risso et al., 1997). Padovani et al. (1998b), com base em medições de descarga sólida total em suspensão realizadas entre 1995 e 1997, estimaram em 35.830 t dia o aporte médio de sedimentos da BAT para a planície. (GALDINO, 2006, p. 38).

Esta situação fez com que o leito do rio fique raso e que as inundações tornem-se frequentes nas regiões situadas nas margens. Isso gera problemas de ordem social, pois as comunidades ribeirinhas não têm mais condição permanecer e migram para a cidade "tornandose moradores das cidades de Corumbá e Ladário", por exemplo. (GALDINO, 2006, p. 41).

O assoreamento provocado por essas 35 toneladas de sedimentos por dia é um dano que jamais será reparado, infelizmente não há outra constatação tão óbvia, sobretudo porque redundou em no seguinte dano ambiental:

Com a intensificação do assoreamento do Rio Taquari no Pantanal (...), principalmente no seu baixo curso, grande volume d'água passou a verter sobre as suas margens, inundando áreas localizadas topograficamente abaixo do nível do leito rio. Essas águas, ao transporem as margens do rio, fizeram com que, em alguns locais, ocorresse o rompimento dessas margens. Esses locais são denominados regionalmente de "arrombados". Os arrombados mais conhecidos são o do "Zé da Costa" e o do "Caronal" (...). Moradores locais relatam que as águas do Rio Taquari começaram a verter pelo Arrombado do Zé da Costa na década de 80, inundando várias colônias rurais. Em 1997, 70\% das águas do Taquari eram desviadas pelo Arrombado do Zé da Costa (Padovani et al., 1998a). Atualmente, o canal do Rio Taquari, a jusante do Arrombado do Zé da Costa, encontra-se desconectado do canal principal e praticamente seco. Com isso, o trecho (de montante para jusante) compreendido entre o Arrombado do Zé da Costa, Rio Negrinho (braço do Rio Taquari), e Rio ParaguaiMirim (braço do Paraguai), tornou-se o novo curso das águas do Rio Taquari até o Rio Paraguai. Esse trecho é utilizado pelas embarcações para o transporte de pessoas e cargas, entre as cidades de Corumbá e Ladário e as fazendas localizadas às margens do Rio Taquari. O Arrombado do Caronal (...) surgiu na década de 90 e estima-se que aproximadamente $50 \%$ das águas do Médio Taquari estão vertendo por esse arrombado. As suas águas estão inundando grandes extensões de terras usadas pela pecuária bovina na Sub-região do Paiaguás. Produtores locais informam que boa parte das águas do Arrombado do Caronal, está desembocando no Rio Paraguai, na localidade de Porto Chané, através do Corixo Mata Cachorro (...). (GALDINO, 2006, p. $38 / 39$ ). 
O rompimento das margens acima descrito produziu um quadro crônico que evoluiu para um desvio do curso do Rio Taquari, especialmente nesses dois arrombados do "Zé da Costa" e o do "Caronal", que é situação dramática para o ecossistema pantaneiro na medida em que o Rio Taquari representa $36 \%$ da irrigação do Pantanal, ou seja, o ciclo pantaneiro estruturado em período de cheias e secas está sendo completamente alterado e tendendo a extinção da vida naquele ecossistema.

Dessa maneira, o levantamento da Embrapa Pantanal (GALDINO, 2006) demonstra claramente que o processo de degradação da Bacia do Rio Taquari é decorrência de políticas realizadas na ditadura civil-militar cujos danos estão evidentes neste momento. Porém, o que torna o quadro preocupante é o fato de que a Bacia do Alto Taquari, degradada pela política de um estado de exceção, corresponde a mais de 1/3 da irrigação do Pantanal e por isso compromete o equilíbrio de todo esse ecossistema. Não menos grave ainda é ratificar que não existem ecossistemas isolados, ou seja, tais impactos também prejudicarão outras regiões além do Pantanal brasileiro, cedo ou tarde.

\section{Conclusão}

O sistema capitalista se desenvolveu e se consolidou como modo de produção predominante no mundo contemporâneo, porém os impactos que produz não são e não estão despercebidos pela humanidade. Contradição é o fato de que apesar dos impactos ambientais explícitos a humanidade não agiu, até agora, para redirecionar os rumos do sistema produtivo e consequentemente da vida, não só humana, na Terra.

O desenvolvimento humano essencialmente passa pela relação do homem com a natureza, pois é neste processo que o trabalho transforma a natureza produz a riqueza e altera o subjetivo do homem permitindo que ele faça a transformação na medida em que também se transforma, porém esse processo foi desfigurado pela lógica do acúmulo, a lógica estruturante do capitalismo. Essa desfiguração fez com que surgisse o Raubbau capitalista que ocasionou uma rachadura irreparável na sociedade capitalista na medida em que alterou substancialmente o metabolismo entre a humanidade e a Terra.

No Brasil o capitalismo arquitetou e efetivou, via forças armadas brasileiras, uma ditadura civil-militar com o único intuito de evitar a ameaça ao processo de acúmulo. Neste sentido, a ditadura civil-militar que nada mais foi do que uma consequência, ou permissão, da lógica do acúmulo, se estruturou em estado de exceção e naturalmente promoveu a suspensão 
da ordem jurídica dominando por intermédio da regra e da exceção, sem nunca deixar de ser formalmente de direito, porém violando todos os direitos humanos e fundamentais possíveis.

Como fruto desse processo de suspensão da ordem jurídica, natural do estado de exceção, as ditaduras são conhecidas pela perseguição, censura, tortura, estupros, assassinatos, sequestros, mas além disso, o que se percebeu é que a ditadura civil-militar destruiu direitos que nem sempre se percebe que é o direito humano e fundamental a uma vida em um sistema ecologicamente equilibrado na medida em que estimulou a expansão do agronegócio sobre o Cerrado com consequências destruidoras sobre o Pantanal, mostrando que o estado de exceção destrói não somente os direitos políticos, mas também direito ambiental.

Como reflexo do estado de exceção que foi a ditadura civil-militar no Brasil restou claro que é impossível que ocorra a suspensão apenas de parte do ordenamento jurídico e por isso a ideia de que só o direito penal sofreu suspensão é errada, pois não dá a dimensão correta do que ocorre nos estados de exceção, ou seja, a suspensão é gênero do qual o direito penal, ambiental são espécies.

A adequada dimensão do que foi o estado de exceção durante a ditadura civil-militar é a de que todos os direitos são suspensos de modo que é preciso explicitar o fato histórico de que a ditadura civil-militar do Brasil não apenas torturou, estuprou, sequestrou assassinou indivíduos, mas também destruiu o equilíbrio ambiental do Pantanal violando direitos difusos e coletivos no que diz respeito a um ambiente ecologicamente equilibrado e saudável.

\section{Referências}

BRASIL. Decreto no 75.320 de 29 de Janeiro de 1975. Brasília: Poder Executivo, 1975.

BRASIL. Ministério do Meio Ambiente, dos Recursos Hídricos e da Amazônia Legal. Plano de Conservação da Bacia do Alto Paraguai (Pantanal) - PCBAP: análise integrada e prognóstico da Bacia do Alto Paraguai. Brasília: MMA/PNMA, 1997. v. 3, 369 p.

BRASIL. Agência Nacional de Águas. Implementação de práticas de gerenciamento integrado de bacia hidrográfica para o Pantanal e Bacia do Alto Paraguai ANA/GEF/PNUMA/OEA: programa de ações estratégicas para o gerenciamento integrado do Pantanal e Bacia do Alto Paraguai: relatório final. Brasília: TDA Desenho \&Arte Ltda., 2004. 316 p.

COMISSÃO NACIONAL DA VERDADE - CNV. Relatório: textos temáticos: Texto 8 Civis que colaboraram com a ditadura. Relatório da Comissão Nacional da Verdade; v. 2, 416 p., Brasília: CNV, 2014.

CONCEIÇÃO, Edmir. História de MS é marcada pela efervescência política e movimentos sociais. Disponível em: $<$ http://www.ms.gov.br/a-historia-de- 
ms/\#: :text=Criado $\% 20 \mathrm{em} \% 201977 \% 20 \mathrm{e} \% 20 \mathrm{implantado}, \mathrm{de} \% 20 \mathrm{MT} \% 20 \mathrm{e} \% 20 \mathrm{criou} \% 20 \mathrm{MS}$. $>$. Acesso em 15 de JUL. de 2020.

FORATO, Sheila. Assoreamento compromete 11 mil km² do Taquari. Disponível em: $<$ http://www.comunidadebancodoplaneta.com.br/profiles/blogs/1741754:BlogPost:304707> Acesso em: 15 de MAR. de 2012.

FOSTER, John Bellamy. A ecologia da economia política marxista. Tradução de Pedro Paulo Bocca. In Monthly Review, v. 63, n. 4, Setembro de 2011.

GALDINO, Sérgio. Impactos ambientais e socioeconômicos na Bacia do Rio Taquari Pantanal / Sérgio Galdino, Luiz Marques Vieira, Luiz Alberto Pellegrin, editores técnicos. Corumbá: Embrapa Pantanal, 2006.

GATTI, Flavio. NUNES, Maria Aparecida. SOBRINHO, Rosangela Alves. Políticas territoriais e desenvolvimento regional no Estado de Mato Grosso. Disponível em: < https://www.unisc.br/site/sidr/2008/textos/149.pdf>. Acesso em: 15 de JUL. de 2020.

JESUS, Luiz Carlos Faria de. A Ocupação dos Cerrados o Polocentro e seus Impactos em Minas Gerais. Monografia apresentada ao Instituto de Economia da UNICAMP, sob a orientação do Prof. Dr. Pedro Ramos. Universidade Estadual de Campinas UNICAMP Instituto de Economia. Campinas - SP. 1988.

KARL, Marx. O Capital: Crítica da Economia Política: Livro I; Tradução de Reginaldo Sant'Anna. 29 ed. Rio de Janeiro: Civilização Brasileira. 2011.

MASCARO, Alysson Leandro. Crítica da legalidade e do direito brasileiro. São Paulo: Quartier Latin, 2003.

MASCARO. Estado e forma política. São Paulo: Boitempo, 2013.

MASCARO. Crise e Golpe. 1 ed. São Paulo: Boitempo, 2018.

MASCARO. Todo direito é um golpe. Disponível em:

$<$ https://blogdaboitempo.com.br/2016/05/25/alysson-mascaro-todo-direito-e-um-golpe/>. Acesso em 28 de FEV. de 2020.

OLIVEIRA, H. de; OLIVEIRA, F. D. A. de; SANO, E. E.; ADÁMOLI, J. Expansão da fronteira agrícola na bacia do alto Taquari utilizando o sistema de informações geográficas SGI/INPE. In: CONGRESSO BRASILEIRO DE CIÊNCIA DO SOLO, 26. 1997, Rio de Janeiro. Viçosa: SBCS, 1997. 4 p. CD-ROM.

PRADO JUNIOR, Caio. História Econômica do Brasil. 31 ed. São Paulo: Editora Brasiliense S. A. 1985.

RESENDE, E. K. de; SANTOS, D. C. dos. Diagnóstico da pesca e aspectos da biologia reprodutiva dos peixes da bacia hidrográfica do Rio Taquari, Mato Grosso do Sul, Brasil. Corumbá: Embrapa Pantanal, 2002. 21 p. (Embrapa Pantanal, Documentos, 25). Disponível em:<http://www.cpap.embrapa.br/publicacoes/>. Acesso em: 15 Fev. de 2012. 
REDAÇÃO TV MORENA. Técnicos do GTI da Bacia do Rio Taquari conferem "in loco" assoreamento. Disponível em:

$<\mathrm{http}: / / \mathrm{rmtonline}$.globo.com/noticias.asp?em $=3 \& \mathrm{p}=2 \& \mathrm{n}=330666>$. Acesso em: 15 de MAR. de 2012.

VIEIRA, L. M.; GALDINO, S.; PADOVANI, C. R. Utilização de pesticidas na agropecuária dos municípios da bacia do alto Taquari de 1988 a 1996 e risco de contaminação do Pantanal, MS, Brasil. Corumbá: Embrapa Pantanal. 2001. 53 p (Embrapa Pantanal. Circular Técnica, 27). Disponível em:

$<$ http://www.cpap.embrapa.br/publicacoes/>.Acesso em: 29 de Fev. de 2012.

WHITROW, G. J. O que é o tempo?: uma visão clássica sobre a natureza do tempo. Tradução: Maria Ignez Duque Estrada. Rio de Janeiro: Jorge Zahar Ed. 2005.

Data de recebimento: 05.03.2021

Data de aprovação: 25.07.2021 